\title{
Entre a natureza 'natural' e a natureza 'sonhada':a propaganda de condomínios nas margens da represa Capivara, Rio Paranapanema, PR
}

Entre la naturaleza 'natural'y la naturaleza de sueño':la propaganda de condominios en las orillas del dique Capivara, Río Paranapanema, PR

Between natural'nature' and'dreamed' nature: the advertisement of condominiums on the banks of the Capivara dam, Paranapanema River, PR

Gilmar Arruda

\section{Resumo}

No final do século XX, na represa Capivara, Rio Paranapanema, divisa dos estados de São Paulo e Paraná, emergiu um novo processo de incorporação das margens do lago por meio de chácaras, como casas secundárias. Alguns desses empreendimentos imobiliários utilizam-se de diversas estratégias de publicidade, como a impressão de fôlderes coloridos para a divulgação do empreendimento. Neste trabalho, pretende-se analisar um fôlder de um condomínio lançado no início dos anos 2000, seguindo duas perspectivas principais: a primeira considera as relações entre a sociedade de consumo, o chamado marketing verde e a era da ecologia; e a segunda investiga quais significados de natureza aparecem representados nesse fôlder. Neste texto investiga-se a ideia de natureza teria sido transformada em um grande shopping center, no qual se vende todos os tipos de produtos e, também, a quais demandas responderia a emergência do fenômeno das chácaras nas margens do lago de Capivara.

Palavras-chave: História ambiental. Marketing verde. Condomínios. Vilegiatura.

Doutor em História pela Universidade Estadual Paulista. Pesquisador e professor no curso de graduação em História e no Programa de Pós-Graduação em História da Universidade Estadual de Londrina. E-mail: arruda@sercomtel.com.br

Recebido em 06/10/2015 - Aprovado em 27/11/2015 http://dx.doi.org/10.5335/hdtv.16n.1.6260 
É um dia claro, no horizonte, muitas nuvens escondem um pouco a presença do sol, mas não anunciam chuva ou tempestades, apenas indicam um clima mais ameno. Suas cores contrastam com as cores das águas de um rio, de azul intenso. Entre o céu cheio de nuvens e o rio plácido e azul, a margem visível apresenta algumas construções e um intenso verde da vegetação. No rio, algumas pessoas em trajes de banho estão em uma plataforma náutica, outras nadam, flutuam, esquiam, velejam ou navegam com jet-skis ou barcos pelas águas calmas, sem correnteza. Porém, essas não são fotografias de pessoas, barcos ou casas reais, são imagens construídas com recursos gráficos computadorizados. Mas existe uma natureza natural: no plano de fundo, uma imagem real, sobre a qual se sobrepõem essas imagens computadorizadas de uma paisagem criada, imaginária, ainda não existente, que se pretende vender. Assim como as imagens das pessoas e parte da natureza, o tempo também parece estar sendo recriado. Talvez seja um final de semana, ou um feriado, mas não se percebe quando é esse momento, o tempo parece estar em suspenso: que horas seriam? Nesse cenário, o tempo não pode estar controlado, pois é um espaço para usufruto dos tempos livres. Essa é a descrição detalhada de um folheto publicitário anunciando um empreendimento imobiliário às margens do Rio Vermelho, no norte do estado do Paraná, no início do ano 2000 (Figura 1). A legenda da imagem indica o que seriam as qualidades do local: "ideal para praticar esportes náuticos como: pescaria, passeios de lancha, jet-ski, esqui aquático, etc.". Um logo esférico, no canto direito, na parte superior, associa lazer e ecoturismo, estabelecendo a relação entre sol, água e lazer. Em letras grandes, abaixo da imagem, uma frase anuncia a motivação para o empreendimento: “Um espaço para lazer e descanso em perfeita harmonia com o meio ambiente".

Figura 1 - Folheto publicitário de empreendimento
imobiliário no Paraná

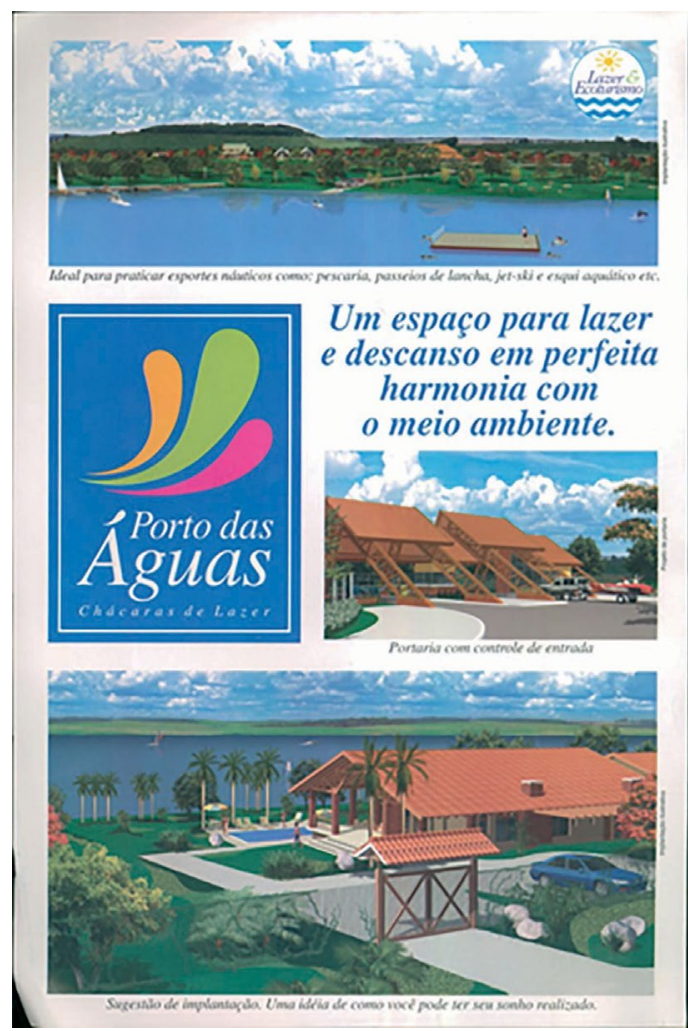

Fonte: folheto publicitário, $2000 .^{1}$

No quadro superior da imagem reproduzida na Figura 1, as nuvens e o espaço do plano de fundo são da natureza natural, no primeiro plano, uma imagem introduzida, ou transformada digitalmente, no lugar do Rio Vermelho, na qual se encontra uma representação dos elementos desejados para aquela paisagem: águas azuis e calmas, ho- 
rizonte límpido e sereno. O quadro da parte inferior do folheto apresenta uma determinada forma de apropriação da natureza, agora transformada em espaço de propriedade privada e constituída como um condomínio fechado. Essa apropriação é apresentada como um espaço que seria perfeito "para lazer e descanso em harmonia com o meio ambiente". Ainda, a legenda do projeto de construção indica uma "ideia de como você pode ter seu sonho realizado".

Esse documento, sem dúvida, é evidência de uma determinada relação dos humanos com a natureza no início do século XXI, marcada pela sociedade de consumo, a prática do turismo, a sociedade do lazer e o desejo de vilegiatura. Como peça publicitária, remete-nos, imediatamente, às relações com o mundo natural, mediadas pelo aparato publicitário, transformado em mercadoria a ser consumida. De outro modo, está associado ao tempo do lazer, do aproveitamento dos tempos livres, às práticas modernas do turismo, nesse caso, com as casas secundárias.

Pretende-se analisar esse documento a partir de duas óticas: primeiramente, considerando as relações entre a sociedade de consumo e o chamado marketing verde, depois, verificando quais permanências e transformações esse tipo de apropriação da natureza representa.

\section{"Esverdeando" a publicidade}

Parece ser, neste momento, lugar comum a afirmação de que o mundo tem se tornado verde. É uma sentença repetida e reafirmada nos mais diversos espaços pú- blicos e privados. Aparentemente, a defesa da natureza, comumente associada à causa ecológica, parece não ter inimigos ou opositores, pelo menos publicamente. Assim, observa-se diversas entidades, desde empresas petrolíferas até movimentos ambientais, colocarem-se a favor da preservação ambiental do planeta Terra. Isto é, claro que não com a mesma perspectiva nem com os mesmos propósitos.

A ecologia, como sinônimo de meio ambiente ou natureza, tornou-se bastante influente nos tempos contemporâneos, condicionando quase todas as falas das sociedades. A partir dos anos 1970 e, mais intensamente, após a realização da Conferência Mundial sobre Meio Ambiente, em 1992, conhecida como Rio-92, essa temática tornou-se crescentemente presente, em todos os espaços, configurando-se como um tema obrigatório. Governos municipais, estaduais e federais, organismos multilaterais internacionais, empresas públicas ou privadas, pequenas ou multinacionais, incorporaram o discurso verde como bandeira e objeto de marketing. Tornou-se mesmo uma ideologia, conforme notava Lívia Barbosa já no início da década de 1990, seria mesmo um valor que legitima com sua marca. O meio ambiente havia se transformado no grande referencial para todos os grupos.

Segundo Livia Barbosa, como estratégia política, a adesão ao tema ecológico, mesmo que superficialmente, constituía-se como a única possibilidade competitiva, na medida em que as grandes utopias, que orientam a busca de um mundo melhor, "[...] começam a desaparecer debaixo das ruínas do socialismo do Leste europeu" (1991, 
p. 14). Dessa forma, o meio ambiente passou a ocupar a pauta de movimentos, práticas e grupos muito diversos, de:

[...] mineradores fazendo pesquisas ambientais para provarem a eficiência de seus métodos; a garimpeiros querendo se reeducar na maneira de utilizarem o mercúrio ou mesmo de abandonarem essa tecnologia; a madeireiros fazendo seminários com deputados verdes; e a todas as instâncias do poder político (municipal, estadual, nacional) se reciclando para saberem como atuar sob a ideologia do verde (BARBOSA, 1991, p. 15).

Essa tendência crescente, apontada por Lívia Barbosa no início dos anos de 1990, tornou-se marca preponderante no início do século XXI. O termo ecologia já havia, naquele momento, assumido um caráter de valor, de discurso político. Para os pesquisadores ligados à análise do discurso, a designação ecologia, que circunscrevia inicialmente uma disciplina da biologia, teve seu sentido deslocado, a partir de determinado momento:

[...] passando a representar também um posicionamento político, ou vários [...] hoje, que falar $d a$ (do lugar da) ecologia ao denunciar agressões ao meio ambiente, ao se mostrar consciente dos problemas ambientais globais e/ou se mostrar atuando de acordo com uma postura ecológica etc. - é estar se colocando dentro do espaço de significação política (SILVA, 1997, p. 142, grifo do autor).

Além de ter se tornado um discurso político, valorizando ou desvalorizando os artefatos, as práticas, as ações sociais e políticas, o assunto também influenciou novas estratégias comerciais e de marketing. Além disso, também atingiu novas práticas do turismo, evidenciadas pela expansão da sua vertente nomeada como ecológica, que seria, para alguns analistas, um "desejo contemporâneo de 'retorno à natureza", uma "tentativa quase literal de reencontrar a natureza por meio do turismo, especialmente sua variação 'ecológica' ou 'ambiental'” (SERRANO, 1997, p. 11).

A ideologia verde alcançou, também, as estratégias de comunicação empresarial, desde as pequenas até as grandes empresas com grandes impactos ambientais, como petrolíferas, produtoras de celulose, mineradoras, etc. Alguns analistas procuraram entender esse fenômeno, interrogando sobre suas origens, motivações e consequências. Michael Howlett e Rebecca Raglon questionaram a percepção dos publicitários e, inclusive, de parte do movimento ambientalista, de que o 'esverdeamento' da 'consciência' das empresas seria uma evidência de como as preocupações ambientais afetam igualmente a todos os atores sociais. Os autores contestaram, também, a ideia segundo a qual a proliferação de propagandas verdes provaria que:

[...] o mercado responderá a qualquer incremento de demanda dos consumidores por produtos mais "naturais" ou "ambientalmente amigáveis". O incremento do número de propagandas desse tipo seria reflexo de um salutar processo de ajustamento descentralizado do próprio mercado aos novos imperativos ambientais (HOWLETT; RAGLON, 1992, p. 53).

Essa perspectiva fundamenta-se na ideia de que o mercado sozinho adapta-se, corrige-se ou normatiza-se em função da relação de oferta e procura. Utilizando-se de uma base de dados com mais de quinhen- 
tos anúncios em jornais e magazines publicados em 1910, 1930, 1950, 1970 e 1990, os autores argumentaram que a utilização de imagens da natureza pelo mercado para vender produtos não é nova e que diversas corporações há muito tentam associar seus produtos com determinados elementos do mundo natural, vistos como benéficos pela maioria do público consumidor. A novidade seria, nos anos de 1990, um “desejo das companhias criarem imagens corporativas nas quais são ambientalmente amistosas ou benignas" (HOWLETT; RAGLON, 1992, p. 54, tradução nossa).

No geral, pouca coisa mudou no uso da natureza para vender produtos, pelo menos desde 1910, o mercado tem consistentemente tentado associar seus produtos a aspectos do mundo natural, criando analogias entre seus produtos e a natureza, apelando para as propriedades naturais de seus produtos, usando simbolicamente objetos naturais e forjando identidades por meio de uma estreita associação com animais e outros elementos naturais. E, principalmente a partir 1970, há um maior crescimento dos anúncios de imagens corporativas que procuram associação com a natureza ou o natural (HOWLETT; RAGLON, 1992, p. 55).

Muitas corporações, como Alcan, Dow e Alcoa, passaram a usar mais cenas naturais para promoverem-se e, em contrapartida, eliminaram as imagens de "[...] fábricas e maquinarias, as quais eram o padrão usual nas propagandas de imagens corporativas nos anos de 1950" (HOWLETT; RAGLON, 1992, p. 55).
Aparentemente, as grandes companhias esperavam evitar associações negativas com, por exemplo, as emissões poluentes. Esse movimento teria começado quando, nos anos 1970, as imagens de fábricas e suas chaminés fumegantes eram “[...] claramente associadas com poluição, as empresas começaram, então, a alinhar-se com as preocupações ambientais" (HOWLETT; RAGLON, 1992, p. 56). Nos anos 1990, as imagens de fábricas eram mais negativas e a ênfase sobre salvar o ambiente produziu uma onda de imagens corporativas gentis e amistosas, contendo crianças, flores, pássaros e árvores.

Howlett e Raglon ressalvam que existem diferenças entre o esverdeamento da publicidade de imagens corporativas e das que promovem um serviço ou um produto. No primeiro caso, a tendência seria um "movimento das imagens tecnológicas passando para as imagens naturais nas publicidades corporativas" (1992, p. 56). Entretanto, quando se refere a produtos e serviços, há "pouca evidência para qualquer novo “esverdeamento" (1992, p. 57).

Os autores questionam, fundamentalmente, os partidários da hipótese do esverdeamento, os quais acreditam que o uso de imagens ecológicas é relativamente um fenômeno novo, surgido, no máximo, nas últimas duas décadas. Além disso, o esverdeamento seria uma evidência da crescente preocupação social com o ambiente e, mais fortemente, prova da flexibilidade do mercado e de sua capacidade não só de responder à crise, mas de providenciar soluções e liderá-las (HOWLETT; RAGLON, 1992, p. 59). 
A publicidade tem usado a associação de produtos com "imagens e símbolos naturais desde o surgimento da propaganda impressa de massa" (HOWLETT; RAGLON, 1992, p. 59). Em suma, "[...] o desenvolvimento da publicidade 'verde' em si mesmo, não pode ser considerado como um fenômeno recente, quer seja em termos de frequência dos apelos a natureza, ou quer seja em termos de tons positivos desses apelos" (HOWLETT; RAGLON, 1992, p. 59). De fato, o marketing verde seria nada mais do que "um passo no longo e contínuo processo que procura convencer o público que um mundo composto por consumidores de mercadorias é "natural" (HOWLETT; RAGLON, 1992, p. 62).

Segundo Howlett e Raglon, o aumento do marketing verde, especialmente das publicidades corporativas, deveria ser visto como uma publicidade de defesa verde, isto é,

[...] grandes companhias tentando provar seu senso de responsabilidade ambiental e sua capacidade para lidar com os problemas ambientais existentes sem a necessidade de novos controles governamentais (1992, p. 64).

Débora Anger (2006), por sua vez, analisou a publicidade verde no início do século XXI, no Brasil, e demonstrou que a utilização da natureza em estratégias de comunicação de grandes empresas brasileiras seguia quatro formas. Em primeiro lugar, apareciam as que faziam uso do meio ambiente com o objetivo de divulgar ou associar a empresa a uma perspectiva mais ampla, como a campanha da empresa de cosméticos Natura, definindo a empre- sa como "uma defensora da responsabilidade social, da biodiversidade e do desenvolvimento sustentável”. Em segundo lugar, as que usavam "imagens e símbolos da natureza para vender produtos e encantar o consumidor", como na campanha de outra empresa de cosméticos, O Boticário, de 2003. Em terceiro lugar, as empresas que se valiam da "estética da natureza utilizada como forma de sedução para a idealização de um mundo melhor". Como exemplo, a autora mencionou a campanha da fabricante de papel Ripasa de 2003. Por último, foram citadas as empresas que se "apropriam de características positivas da natureza, tentando associá-las ao perfil da empresa", como forma de criar uma imagem positiva para a suas atividades, como o caso da campanha da Petrobrás de 2003 (2006, p. 7-13).

Como no estudo de Howlett e Raglon, as campanhas publicitárias estudadas por Anger guardam relações com o processo de propagação da ideologia verde ou da ecologização da sociedade dos últimos anos do século XX e início do século XXI. Débora Anger argumentou que a "conversão" ecológica das estratégicas de comunicação das empresas derivava-se nem tanto por pressão dos ambientalistas ou exigências legais,

[...] mas principalmente por outros fatores do mercado, como por exemplo, a necessidade que têm de alcançar uma certa excelência ambiental para obter selos verdes, do tipo ISO 14.000, a fim de evitar barreiras comerciais a seus produtos no exterior (2006, p. 5). 
Porém, ao mesmo tempo em que matiza a influência do movimento ambientalista, ou de regulamentação governamental como explicação para a mudança nas estratégias de marketing das empresas, a autora argumenta que um dos motivos para o movimento de transformação daquelas estratégias publicitárias estaria em uma opinião pública mais consciente, para a qual uma imagem de companhia poluidora seria muito negativa:

Para tornar a opinião pública favorável e ganhar simpatia de seus consumidores, começou a ficar clara a necessidade de comunicar essa nova preocupação para o público. Assim, a propaganda tornou-se peça básica de informação das ações pró-ambiente (ANGER, 2006, p. 5).

Assim, tanto na análise de publicidade corporativa de empresas norte-americanas quanto nas de empresas brasileiras, pode-se concluir que a movimentação em direção a uma "imagem verde" parece fazer parte muito mais de uma defesa do aumento de regulamentação e restrição das atividades do que de um convencimento em defesa da natureza. No entanto, a ecologização da sociedade, como fenômeno de opinião pública, acabou por pressionar as empresas a modificarem alguns aspectos de seu posicionamento público, mesmo que apenas por marketing.

\section{Naturezas à venda}

Não é apenas nas estratégias publicitárias de venda de mercadorias e produtos que aparecem associações com aspectos da natureza. Em alguns anúncios, a própria natureza, ou determinadas representações do que seria a natureza, está sendo vendida. Isso fica muito evidente em anúncios do mercado imobiliário das grandes cidades, especialmente quando ofertam condomínios fechados. A propaganda "esverdeada" está presente também em outras perspectivas, como nos anúncios de atividades turísticas, desde o esquema já clássico do turismo sol, praia e mar -, até em produtos (pacotes) denominados de ecoturismo. O esverdeamento das estratégias de marketing pode ser observado ainda em anúncios imobiliários de empreendimentos distantes das áreas consignadas como naturais. Isso parece ser um fenômeno globalizado, como veremos adiante, restando verificar possíveis particularidades no nosso objeto inicial: loteamentos de chácaras de lazer no reservatório Capivara, no Rio Paranapanema, Paraná.

Daniel Hiernaux-Nicolás (2009, p. 111) analisou alguns aspectos do turismo residencial no México. ${ }^{2}$ Após apontar a extensão dessa prática de turismo no mundo todo, em especial no mundo europeu, onde cerca de $15 \%$ das residências seriam do tipo casas secundárias, que atingiria mais de $32 \%$ na Espanha, o autor considera que o fenômeno é pouco conhecido no México. Embora não ultrapassasse $3 \%$ das residências mexicanas, cerca de 600 mil casas, percentual pequeno se comparado à Europa, seria um fenômeno em expansão, pelo menos até a crise financeira de 2008.

$\mathrm{O}$ autor questiona-se sobre o que haveria motivado tanto construtores como consumidores a optar por esse tipo de produto. Segundo ele, em parte, a motivação para a expansão desse tipo de produto imo- 
biliário no México estaria na então recente liberalização da economia mexicana, que levou ao surgimento e à intensificação de vivendas em conjuntos, conhecidas como fraccionamentos, e também de apartamentos, pouco usuais no México (HIERNAUX-NICOLÁS, 2009, p. 112). Entretanto, para além das causas estruturais e financeiras, o autor procurou entender o imaginário que estava subjacente nas origens do fenômeno de expansão das casas secundárias no México. Nesse sentido, sua análise abrirá algumas perspectivas de entendimento do objeto deste trabalho.

A força do imaginário nas atividades de turismo, nesse caso na expansão das casas secundárias destinadas a esse fim, encontra explicação em uma literatura recente e em expansão, que, segundo Hiernaux-Nicolás, ressalta, sobretudo,

[...] a crescente convicção de que não é possível pensar que o turismo é construído e prospera somente a partir das condições e forças desencadeadas na esfera do econômico: existem poderosos imaginários sociais que os sustentam (2009, p. 114).

Outro fator sobre o turismo, destacado por Hiernaux-Nicolás (2009, p. 115-117), é a "Busca do Éden", seja devido ao imaginário religioso, sobre a perda do paraíso, ou resultante da insatisfação com a vida e o cotidiano na residência principal. Nesse caso, a busca pelo Éden, por meio de uma viagem, relaciona-se a uma fuga da vida cotidiana na modernidade. A procura pelo paraíso, ou pelo menos pelas evidências disso, no imaginário do turismo pode ser percebida quando se analisam os folhetos publicitários, com as descrições dos locais de viagens ou mesmo nos nomes ou adjetivos dados aos empreendimentos imobiliários das casas secundárias. O principal pressuposto do autor é que a busca do paraíso é um imaginário profundo que atravessa as sociedades ocidentais. No centro do imaginário edênico estaria o conceito de natureza.

$\mathrm{O}$ turismo em geral, o residencial em particular, sustentar-se-ia na recuperação de uma estreita relação com a natureza, que foi destruída pela urbanização intensiva. Entretanto, esse pressuposto generalizante encobriria muitas situações que não se explicam totalmente por ele (HIERNAUX-NICOLÁS, 2009, p. 118).

A natureza, nesse caso, assemelha-se, ou é associada, à ideia de campo, de zona rural. Em termos concretos, a casa de campo típica, ou como protótipo de definição, estaria em um lugar remoto, isolado, ou de difícil acesso, em oposição ao mundo urbano. A existência de tal casa só seria possível no contexto europeu e/ou canadense, em que as condições de vida e segurança permitiriam a manutenção e vivência sem riscos pessoais. No caso do México, foco de estudo de Hiernaux-Nicolás, as casas de campo são uma adaptação. Elas estão fora dos grandes centros urbanos, mas perto de pequenas cidades ou comunidades com tamanho suficiente para garantir a segurança pessoal bem como o fornecimento de serviços básicos. Algumas dessas casas, devido ao tamanho da propriedade, podem prescindir dessa proximidade, os proprietários possuem condições financeiras para contratar e manter funcionários residentes em tempo integral (HIERNAUX-NICOLÁS, 2009, p. 118). 
Entretanto, a maior parte das casas secundárias de campo, no caso mexicano, o que se aplica também, em parte, ao Brasil, estão localizadas em um condomínio fechado e isolado do exterior. Embora seus proprietários idealizem estar no campo, eles estão fechados em suas próprias casas (HIERNAUX-NICOLÁS, 2009, p. 119). Trata-se de um triplo isolamento. A vida campestre, ou o que se imagina dela, resume-se a organizar e cuidar do jardim das casas. Esse jardim da "pseudocasa de campo" (HIERNAUX-NICOLÁS, 2009, p. 119) reflete a intenção de uma inserção na vida do campo. O verde presente nesses jardins e nos condomínios seria testemunha disso. Gramados cuidadosamente aparados em oposição aos pastos reais das propriedades rurais, a presença de uma infinidade de plantas decorativas, como as buganvílias, fontes de água, carros de boi, ou parte deles, como as rodas, evidenciariam essa disposição. Poderia, ainda, ser associado, no caso do México, a um imaginário do mundo rural presente nos filmes mexicanos dos anos 1940, sendo, assim, um retrato da memória coletiva do mundo rural desaparecido.

Trata-se da tentativa de retomar o controle do tempo, fugindo da opressão e da velocidade impostas pela hipomodernidade, apesar de a tirania do tempo ter sido substituída pela tirania do deslocamento. $\mathrm{O}$ deslocamento cria uma espécie de sensação mental de desprendimento das obrigações cotidianas. Os modelos das casas, reconstruindo certos aspectos de um mundo desaparecido, e ainda a expectativa de que as casas secundárias possam servir para reatar laços ou cotidianos familiares, são aspectos que se aproximam do que pode ser obser- vado na realidade brasileira ou, em particular, na emergência da febre das chácaras no entorno da represa Capivara recentemente (ARRUDA, 2013). Mas, ressalta-se, nesse caso, a relação entre as casas secundárias e o retorno à natureza, quer seja ela imaginada como o paraíso, o campo ou o verde. Uma característica que parece estar presente em todos os casos estudados do fenômeno das casas secundários nos tempos recentes.

A presença da ideia de natureza associada a empreendimentos imobiliários, evidenciada em estratégias e materiais de marketing e publicidade, não se restringe aos imóveis destinados ao lazer (segunda residência), como casas no campo, nas montanhas, nas praias, mas aparece também em anúncios de imóveis no espaço urbano. Wendel Henrique (2006) e, mais recentemente, Antonio Helio Junqueira (2010) analisaram essa temática na cidade de São Paulo, a maior metrópole brasileira. Embora os pontos de partida da análise dos dois autores sejam diferentes, ambos aproximam-se na avaliação sobre as origens e funcionalidades que a ideia de natureza representa atualmente no mundo urbano. Segundo Henrique:

[...] vive-se um novo período de profundas transformações nas ideias de natureza; além da permanência dos modelos quantitativos, observa-se uma restauração de uma ideia mítica da natureza, um reencantamento da natureza, não com um viés 'sobrenatural', mas, sim, seguindo um projeto específico de valorização financeira da natureza (2006, p. 65).

Assim, também para Henrique (2006, p. 70), qualquer menção ou associação a uma ideia de natureza torna-se símbolo de qualidade de vida, transformando-se em valor 
econômico, ou valorizando monetariamente, em especial, os produtos imobiliários. Isso ocorreria tanto na cidade de São Paulo quanto em Florianópolis, mas essa cidade, em particular, apresentaria alguns aspectos diferenciados. Em São Paulo, um exemplo da:

[...] grande realização humana, artefato por excelência e aparente negação da natureza, [...]. A natureza, metáfora ou metonímia, que já havia sido reificada e incorporada à vida social, ao longo da história do homem, é apropriada e até mesmo produzida, com o objetivo de valorização monetária de objetos/mercadorias nos mais variados segmentos da produção e dos serviços (HENRIQUE, 2005, p. 1).

Em Florianópolis, por sua vez, essa ideia não seria apenas uma ilusão, pois os empreendimentos imobiliários são vendidos explicitamente como sendo locais de natureza. Pode-se concluir que por ser um local, ou uma cidade, no qual o artefato humano é extremamente preponderante, como na cidade de São Paulo, ou em uma cidade, na qual, apesar da urbanização, a natureza natural ainda é predominante, pelo menos na paisagem, a ideia de natureza é manejada para emprestar valor a produtos da maquinaria capitalista contemporânea. Seria, então, a natureza transformada em um grande shopping center, no qual todos os tipos de produtos são vendidos. Mas não seria

[...] apenas uma ilusão, como se transforma(ria) no mais puro ato enganador que o 'marketing verde' propaga. É a comprovação da alienação, do pagamento por um produto caro, a natureza nativa, mas que, na verdade, é o pagamento para ser enganado (HENRIQUE, 2006, p. 70).

Nesse sentido, a enganação, seria embrulhada em uma estratégia de disneyficação da natureza, ideia encampada do geógrafo David Harvey. A disneyficação da natureza teria, segundo a interpretação de Henrique, as seguintes características:

Uma suposta felicidade, harmonia e espaços sem conflitos - uma fuga para fora do mundo real; uma construção feita para entreter; uma história inventada; um cultivo de uma nostalgia de um passado mítico; uma perpetuação do fetiche pela cultura da mercadoria; um agregado de objetos e coisas de todo o mundo numa ideia de diversidade e existência multicultural, mesmo que tudo se dê na forma de compartimentos; um lugar limpo, sanitarizado e mitologizado, esteticamente perfeito (2004, p. 105).

Apesar de trazer importantes contribuições para o entendimento do valor que a ideia de natureza assume nas grandes cidades, como em São Paulo ou Florianópolis, a análise de Wendel Henrique parece deixar uma questão sem resposta: Por que, apesar de ser uma ilusão, um truque, os indivíduos continuam a se engajar nesse mundo de Disney, comprando os artefatos colocados à venda? Nesse sentido, a análise de Antonio Helio Junqueira pode trazer algumas pistas para tentar-se responder os porquês de os indivíduos continuarem, livremente, comprando ingressos para a Disneylândia.

Inicialmente, Junqueira aponta como os desejos, ou melhor, as ideias veiculadas nas propagandas de produtos imobiliários aparecem:

[...] os conceitos e os sentidos no imaginário da habitação desejável são construídos nos espaços da contraposição entre a poluição urbana e a pureza do ar das áreas verdes; entre o ambiente artificialmente construído e a natureza preservada (2010, p. 2-3). 
Uma carência, decorrente do urbano, especialmente, na história brasileira da segunda metade do século XX, é a origem desse desejo que aparece na publicidade. Lembrando a definição de Henrique, o urbano é o maior artefato construído pelos humanos, portanto, a natureza não estaria presente senão na forma de natureza morta.

$\mathrm{O}$ estudo de Junqueira tomou como fonte os anúncios de empreendimentos publicados no jornal O Estado de S. Paulo entre 2007 e 2010, tendo descartado aqueles que envolviam as chamadas segundas residências, como casas de praia, chácaras, casas de montanha, etc. $\mathrm{O}$ autor baseia-se no contexto de ausência de áreas verdes nas grandes cidades, consideradas uma necessidade para o bem-estar e a saúde da população urbana. Esse contexto explicaria a razão da presença dessas áreas verdes nos anúncios publicitários de empreendimentos imobiliários, na grande metrópole:

[...] as áreas verdes preservadas e os grandes projetos paisagísticos tornaram-se importantes chamarizes dos empreendimentos imobiliários, especialmente aqueles focados no consumo das classes média alta e alta (2010, p. 6).

A retórica do verde chega mesmo a propor uma inversão do estilo de vida, "prometendo uma transposição da rotina urbana para as lidas de uma 'autêntica' vida rural" (2010, p. 6). Junqueira afirma:

[...] o conjunto de anúncios selecionados confere elevado valor simbólico e inquestionável centralidade discursiva à natureza - na forma do paisagismo público ou privado, construído ou dos bosques e reservas preservados (2010, p. 7).
De certa maneira, o autor ecoa o que Livia Barbosa já afirmara alguns anos antes. Está claro, porém, para o autor, que essa conclamação de volta à natureza, representa apenas um recurso retórico no campo da publicidade, pois:

[...] esta propalada "volta à natureza"' no interior do espaço urbano constitui-se apenas em uma questão retórica, sem efeito concreto sobre a qualidade da vida nas cidades (2010, p. 7).

Então, se trata-se apenas de uma questão retórica, mais uma vez, por que os indivíduos continuam investindo suas poupanças e seus projetos de vida em uma quimera? $\mathrm{O}$ autor considera que:

[...] a prevalência de determinadas características constitutivas dos novos tipos de lançamentos imobiliários contemporâneos - nos quais se buscam valorizar grandes áreas verdes comuns, espaços de lazer e entretenimento condominial e projetos paisagísticos cada vez mais espetaculares e impactantes - fazem sentido e são consumíveis por que vão de encontro ao conjunto de aspirações discursivamente construído e simbolicamente representativo do status do morar bem (JUNQUEIRA, 2010, p. 2).

A publicidade age, portanto, como construtora de distinção e satisfação. Morar ou comprar algum produto significa muito mais do que o usufruto de sua materialidade. No mundo contemporâneo, no tempo do sistema mágico (WILLIAMS, 2011), ${ }^{3}$ o produto vale muito mais, talvez, exclusivamente, não pelo valor de uso, mas pela possibilidade de construir distinções sociais. Como afirma Junqueira: 
No âmbito do sistema classificatório que carrega em seu bojo, a publicidade articula os valores associados à distinção e serve para promover a diferenciação social (2010, p. 7).

No mundo em que o espaço, a natureza por definição, transformou-se em mercadoria, não basta ter um pedaço dele para se distinguir. Embora a propriedade privada desse espaço, dito natureza, seja uma das mais poderosas ferramentas de distinção no mundo contemporâneo, ela não é suficiente. No mundo urbano, no qual, aparentemente, todos os espaços já foram transformados em propriedades privadas, a posse de uma delas não garante a distinção. Talvez o tamanho de seu espaço, a localização, a paisagem, etc., possam torná-lo exclusivo, portanto distinto.

No entanto, de acordo com Henrique e também Junqueira, o fator de distinção mais poderoso seria, como no caso dos diamantes, a raridade. A natureza parece ser o diamante do mundo urbano. Então, adquirir um produto imobiliário que anuncia ter essa raridade torna o comprador (morador) um cidadão distinto dos demais. Mas, ainda assim, permanece a questão da ilusão: voluntária ou imprescindível? Segundo Henrique, trata-se, podemos estar fazendo uma análise esquemática, do fetiche da mercadoria. Já para Junqueira, existem algumas complexidades a serem examinadas, embora também acompanhem a noção do espaço transformado em mercadoria e, portanto, inserido na maquinaria do mercado.

Destacam-se, aqui, apenas os aspectos sobre os usos da ideia de natureza na venda de produtos imobiliários, presentes na análise de Junqueira (2010, p. 10). Um detalhe importante, mencionado na análise desse autor, é sobre como determinados aspectos dos empreendimentos, que antes tinham destaque, como a disposição da planta interna, as comodidades do imóvel, cedem lugar, ao longo do período analisado, para a localização, destacando-se a proximidade a áreas verdes, os projetos paisagísticos, etc.

Se a natureza, as áreas verdes e as denominadas áreas de lazer dos condomínios horizontais e verticais são tão destacadas pelos anúncios publicitários, seria de se esperar que esses espaços fossem, depois de vendidos e ocupados os empreendimentos, muito utilizados. Mas, ironicamente, uma evidência a ser analisada, a realidade é que esses espaços estão "condenados ao vazio e à inatividade permanentes" (JUNQUEIRA, 2010, p. 13).

Quanto ao problema sobre a opção dos indivíduos em acreditar na natureza disneyficada, segundo Junqueira:

Portanto, crendo que o receptor - que se confunde aqui com o potencial cliente comprador do imóvel anunciado - seja possuidor de um senso crítico minimamente estruturado para a refutação da mensagem ludibriosa, instaura-se um impasse. Afinal, como entender, então, a insistência da publicidade imobiliária em ancorar o seu discurso retórico em elementos decididamente inconsistentes? (2010, p. 17).

A resposta do autor a essa questão refere-se ao cinismo, uma vez que as promessas da publicidade, todos saberiam, seriam realmente impossíveis de serem realizadas. Logo, a publicidade é cínica, mas os compradores também aderem a esse cinismo coletivo, pois, no mundo contemporâneo, nada seria realmente feito para durar, e: 
Em última instância, isto nos faz passar de uma sociedade de satisfação administrada para uma sociedade da insatisfação administrada na qual ninguém realmente acredita nas promessas de gozo veiculadas pelo sistema de mercadorias (já que elas estão postas para serem descartadas), a começar pelo próprio sistema, que as apresenta de maneira cada vez mais auto-irônica e 'crítica' (SAFATLE, 2008 apud JUNQUEIRA, 2010, p. 18, grifo do autor).

\section{A natureza sonhada}

A utilização de ideias de natureza em propagandas de produtos associados ao turismo parece ser uma realidade globalizada. A imagem apresentada na Figura 2 refere-se à represa de Alqueva, no sul de Portugal, na fronteira com a Espanha.

Figura 2 - Represa de Alqueva, Portugal

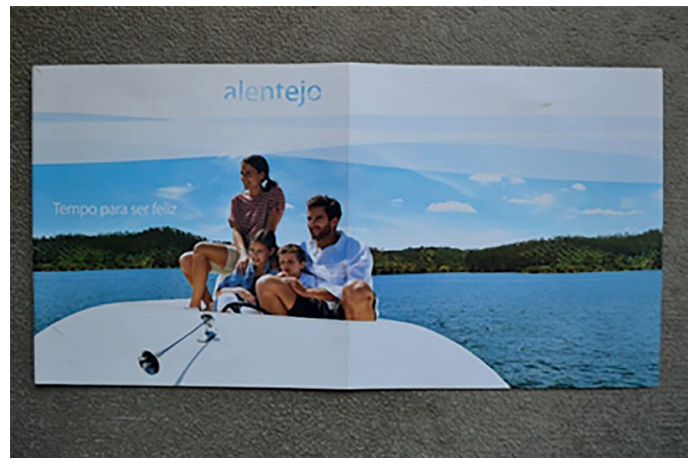

Fonte: fôlder de divulgação do turismo no lago de Alqueva. Produzido por Turismo em Alqueva. Disponível em: $<$ http://www.turismoalqueva.pt/>.

Outros documentos podem ser encontrados facilmente na rede mundial de computadores. Acredita-se que não seria possível, metodologicamente, uma pesquisa que pudesse determinar uma porcentagem confiável sobre a incidência do termo natu- reza, ou sua referência, em panfletos, sites, anúncios em jornais, televisão, cinema, etc., relacionados ao turismo. A intenção, nesse caso, é demonstrar a mundialização da associação.

Entretanto, apesar de existir evidências suficientes para a comprovação da globalização no uso das ideias de natureza na publicidade em uma infinidade de produtos, independentemente de países e culturas, o desafio é procurar respostas para as especificidades locais. Em outros termos, a questão é: a demanda pela represa de Alqueva, em Portugal, teria as mesmas origens, motivações, semelhanças nos grupos sociais que as que motivaram o surgimento do condomínio Porto das Águas, às margens do Rio Vermelho, em Porecatu, PR? Não há, nos objetivos desse texto, possibilidade de se fazer uma história comparada em relação ao mundo português ou europeu, embora seja necessário considerar as ressalvas sobre as casas de campo no México, mencionadas anteriormente por Daniel Hiernaux-Nicolás.

Faz-se necessário, então, localizar o processo histórico no qual as margens do Rio Vermelho passaram a ser mercadoria. Um dos primeiros movimentos desse processo, no grande espaço circunscrito por quatro rios, localizado no norte do atual estado do Paraná, foi a instalação da Colônia Militar do Jatai, no início dos anos 1850, na margem direita do Rio Tibagi, e do Aldeamento de São Pedro de Alcântara, em sua margem esquerda (ARRUDA, 2013). Nesse momento, registra-se a transformação da natureza em terra, portanto mercadoria possível de ser vendida e comprada no mercado, ou a grande transformação, como a denominou Karl 
Polanyi (2000). Essas duas ações no baixo Tibagi representaram o início do processo de instalação concreta de nova biota e de novas populações na região. $\mathrm{O}$ início do século $\mathrm{XX}$, com a marcha da cafeicultura associada ao processo de urbanização, significou um momento de aceleração da grande transformação da floresta em terra.

O surgimento de Londrina, atualmente a maior cidade localizada na bacia do Tibagi, no início da década de 1930, está relacionado a esse processo, que encontra suas origens em um quadro mais amplo, iniciado no final do século XIX. Uma das características desse processo foi a busca por novas áreas de produção e fornecimento de matéria-prima, que levou os países centrais a "vasculhar" o mundo.

A partir da segunda metade do século XIX, o imperialismo busca suas potencialidades de lucro em todo o planeta. Como disse Eric J. Hobsbawm (1988, p. 29), todas as partes do mundo tornaram-se conhecidas e mapeadas. Com poucas exceções, já não se tratava de descobertas, mas era uma espécie de esforço atlético, com toques de desafios pessoais ou nacionais, como tentativas de vencer a natureza dos ambientes mais inóspitos, como o Ártico e a Antártica. Esse movimento afetaria a bacia do rio Tibagi, assim como a cidade de São Paulo, com a expansão da atividade cafeicultora impulsionada pelos novos tempos de ritmo acelerado (SEVCENKO, 1998).

O que motivou a ocupação da bacia foi a terra, aquilo que Donald Worster, seguindo Karl Polanyi, chamou de "simplificação da natureza":
Todas as forças e interações complexas, seres e processos que designamos como "natureza" (às vezes até elevada ao status honorífico de uma natureza capitalizada), foram reduzidas a uma simplificada abstração, "terra", [...] a terra tornou-se "mercantilizada"; ela veio a ser considerada como se fosse uma mercadoria e, por essa maneira de pensar, foi disponibilizada para ser comercializada sem restrição (WORSTER, 2003, p. 12).

Somente a partir dos anos 1920, a expansão da cafeicultura atingiu a margem leste do Rio Tibagi, embora já tivesse avançado até o espigão que separava os rios Cinza, afluente do Paranapanema, e Tibagi. Na década de 1930, inicia-se a moderna colonização na margem oeste, com o surgimento do núcleo urbano de Ibiporã e, depois, Londrina. Até a década de 1960, a cafeicultura representava a principal atividade agrícola e econômica desenvolvida na parte baixa da bacia do Tibagi. Pode-se designar esse período de grande transformação como: “O primeiro rural: da floresta à agricultura familiar", que representaria as transformações da grande floresta estacional semidecidual, que cobria grande extensão da região entre os rios Tibagi, Ivai, Piquiri e Paranapanema.

Essa primeira fase pode ser delimitada entre as décadas de 1930 e 1960 . Nesse momento, a transformação evidencia-se pelo surgimento do urbano e de todos os seus artefatos tecnológicos, como estradas, propriedades, etc. A natureza é, então, dividida em lotes, uma grande parte constituída de pequenas propriedades, introduzindo uma gigantesca quantidade de novas espécies vegetais e animais. $\mathrm{O}$ motor econômico desse processo foi a produção de café, mas não era 
o único motivo que impulsionava novas populações até esse território.

No início dos anos 1960, motivações oriundas do mundo urbano, da modernização da agricultura cafeeira, aceleradas por um grande desastre socioambiental em $1963,{ }^{4}$ começam a alterar aquela estrutura socioagrária iniciada já por volta dos anos 1930, resultando no que viria a ser conhecido como o complexo do agrobusiness.

Tabela 1 - Evolução da população de Londrina, 19352000

\begin{tabular}{l|r|r|r|r|r}
\hline \multirow{2}{*}{ Ano } & \multicolumn{2}{|c|}{$\begin{array}{c}\text { População } \\
\text { Urbana }\end{array}$} & \multicolumn{2}{c|}{$\begin{array}{c}\text { População } \\
\text { Rural }\end{array}$} & \multicolumn{1}{c}{$\begin{array}{c}\text { População } \\
\text { total }\end{array}$} \\
\cline { 2 - 5 } & Número & \multicolumn{1}{|c|}{$\%$} & Número & $\%$ & \\
\hline 1935 & 4.000 & 27 & 11.000 & 73 & $\mathbf{1 5 . 0 0 0}$ \\
1940 & 19.100 & 25,4 & 56.196 & 74,6 & $\mathbf{7 5 . 2 9 6}$ \\
1950 & 34.230 & 47,9 & 37.182 & 52,1 & $\mathbf{7 1 . 4 1 2}$ \\
1960 & 77.382 & 57,4 & 57.439 & 42,6 & $\mathbf{1 3 4 . 8 2 1}$ \\
1970 & 163.528 & 71,7 & 64.573 & 28,3 & $\mathbf{2 2 8 . 1 0 1}$ \\
1980 & 266.940 & 88,5 & 34.771 & 11,5 & $\mathbf{3 0 1 . 7 1 1}$ \\
1991 & 366.676 & 94 & 23.424 & 6 & $\mathbf{3 9 0 . 1 0 0}$ \\
2000 & 433.369 & 96,9 & 13.696 & 3,07 & $\mathbf{4 4 7 . 0 6 5}$ \\
\hline
\end{tabular}

Fonte: elaboração do autor com base em dados dos Censos demográficos do Instituto Brasileiro de Geografia e Estatística.

O contexto da cidade de Londrina, a maior da região, é um dos mais relevantes para se entender esse processo de transformação da paisagem, ou da natureza em terra, mercadoria que pode ser vendida e comprada, seja em termos de terra para propriedades rurais, seja como solo urbano. Essa cidade teve um rápido crescimento populacional, pois, em meados dos anos 1940, já contava com aproximadamente $50 \mathrm{mil}$ habitantes. Na década de 1960, a população ultrapassou os 100 mil habitantes. Nos anos 1980, atingiu 300 mil, e atualmente passa dos 500 mil habitantes. A maior parte desse contingente populacional era oriunda das pequenas cidades da região ou de pessoas que habitavam a zona rural, cuja estrutura socioagrária fora destruída pela expansão do complexo do agrobusiness; homens e mulheres que haviam nascido e crescido nas atividades agrícolas, nas quais o tempo de trabalho e descanso não está, necessariamente, marcado e separado pelo ritmo da produção industrial.

Além da periodização relacionada à transformação da natureza em terra de agricultura, existem outros fatores que demarcam periodizações distintas e complementares. A partir da década de 1940, os rios passaram a ser apropriados pela sua capacidade de energia hidráulica, seria o início da era das grandes barragens. A partir dessa década, a febre da eletricidade instalou-se nos projetos estatais de desenvolvimento e incorporação das áreas dos interiores.

O Rio Paranapanema foi então mapeado como potencial gerador de energia elétrica, nos anos 1960, por um consórcio multinacional chamado Canambra Engineering Consultants. Vários dos estudos e projetos saíram do papel nas décadas seguintes. Atualmente, ao longo de seu curso, existem oito barragens para a produção de energia elétrica. A área coberta pelos lagos dessas barragens cobre aproximadamente $1.000 \mathrm{~km}^{2}$. A maior delas, a represa Capivara, construída nos anos 1970, na região de Porecatu, PR, e Taciba, SP, tem um reservatório com mais de $500 \mathrm{~km}^{2}$ de área alagada. A influência do barramento do curso do rio ultrapassa $70 \mathrm{~km}$ a montante do Rio Paranapanema e cerca de 50 km no curso do Rio Tibagi, prin- 
cipal afluente da margem esquerda daquele rio. A barragem Capivara é, então, uma referência significativa da história ambiental dessa bacia hidrográfica.

O surgimento da era da ecologia e/ou da ecologização da sociedade, as transformações na estrutura socioagrária e a desumanização do campo, como se pôde observar na Tabela 1, com a constituição de uma sociedade urbanizada, com tempos sociais da modernidade, seriam os vetores associados que criaram as condições necessárias para o surgimento dessa nova forma de apropriação da natureza, a vilegiatura.

A urbanização e o aburguesamento da sociedade brasileira, ${ }^{5}$ especialmente nas cidades do interior, com o surgimento das médias cidades, como Londrina $(500 \mathrm{mil}$ habitantes) e Maringá (300 mil habitantes), ambas a cerca de $60 \mathrm{~km}$ ao sul do Rio Paranapanema, são outros fatores sociais que se somam aos já mencionados e que criam as condições sociais e de sensibilidade para desenvolver as novas práticas junto ao lago: as chácaras de lazer em loteamentos ou condomínios fechados, os passeios de barcos, as casas secundárias, as pousadas e colônias de férias de associações, de sindicatos de trabalhadores e de instituições.

A natureza, que havia sido transformada na mercadoria-terra, sofre, então, uma nova transformação e passa a ser apropriada como uma nova mercadoria. Esse novo tempo-espaço é criado pela prática do turismo, ou da casa secundária. O capitalismo transformou radicalmente as organizações territoriais anteriores, de forma crescentemente homogênea, na medida em que as técnicas de comunicação e transporte evoluíram: “O espaço tornou-se uma mercadoria e a expansão da dominação espacial uma necessidade [...]" (GAMA, 2008, p. 20).

Quaisquer espaços e atividades desenvolvidas tornaram-se objeto da valorização enquanto mercadoria. Os espaços usados para usufruir o tempo livre não poderiam ser uma exceção:

O capitalismo já não se apoia somente sobre empresas e o mercado, mas sobre o espaço. Há também o ócio. Com a indústria do ócio o capitalismo apoderou-se dos espaços que ficaram vazios: o mar, a praia, a alta montanha. Criou uma indústria nova, uma das mais poderosas: a indústria do ócio (LEFÈBVRE, 1974, p. 221 apud GAMA, 2008, p. 20).

Os espaços destinados às casas secundárias eram antes florestas, territórios indígenas, que passaram a ser terra agriculturável. Com a represa, parte dessa área foi alagada. A legislação ambiental transformou as margens em área de preservação. A maior parte do espaço das pequenas propriedades foi incorporada no sistema do agrobusiness. Uma pequena parte tornou-se espaço-mercadoria para loteamentos, para ser consumida, apropriada e transformada pela indústria do ócio.

Esse é o contexto do surgimento dessa nova demanda sobre a natureza, agora não mais apenas relacionada ao processo do surgimento dos ecossistemas reorganizados em agroecossistemas, mas como mercantilização da vilegiatura, ou seja, a venda de um desejo de procura por uma natureza sonhada, representada pelas peças publicitárias anunciando os terrenos à venda em condomínios de casas nas margens dos rios da 
região, em particular às margens da represa Capivara, no Rio Paranapanema.

A emergência das casas secundárias à beira da represa, que na região são denominadas chácaras, torna-se um fenômeno notável após os anos 1980. Um comerciante denominou esse movimento de a febre das chácaras (ARRUDA, 2013). Porém, essas chácaras são muito diversas entre si, desde o processo de constituição do parcelamento do terreno à estrutura de venda (incluindo ou não imobiliárias das grandes cidades da região, estratégias publicitárias e de marketing, inclusive com anúncios em redes de televisão, ou simples parcelamento de pequenos sítios, comercializados individualmente ou por corretores locais).

Além disso, existem diferenças substanciais na constituição e organização do terreno dessas chácaras. Se em condomínios fechados, como o representado pela Figura 1, existem projetos arquitetônicos, ajardinamento, arruamentos, muros de separação, portarias de entrada, vigilância itinerante, etc. Em outros parcelamentos, constituem-se como simples divisão do terreno, sem nenhuma condição prévia para as construções. Isso representa, também, significativas diferenças de valores envolvidos na aquisição e construção dessas propriedades. Um imóvel, no condomínio referenciado, pode ultrapassar a casa de um milhão de reais, conforme busca na rede mundial de computadores. Mas, talvez, não seja o valor monetário, a principal evidência da diferenciação das perspectivas envolvidas na aquisição desse tipo de iniciativa.

Facilmente, pode-se observar que as propriedades localizadas no empreendi- mento Porto das Águas, seja no folheto publicitário, como ilustrado na Figura 1, ou no site do condomínio (disponível em: <http:/ / www.portodasaguas.com.br/>), têm formas de organização do espaço interno que se aproximam daquela discutida por Daniel Hiernaux-Nicolás, para o caso do México. $\mathrm{O}$ limite de acesso à natureza dessas casas é a organização de um jardim, com grama e plantas, indicando extrema organização da natureza. Uma pacificação ou estetização do que teria sido, um dia, um mundo natural. Não são casas de campo, no sentido do protótipo mencionado por Hiernaux-Nicolás. Elas padecem do triplo isolamento imposto pelo sistema de condomínios fechados.

Pode-se questionar se $\mathrm{o}$ acesso às águas do Rio Vermelho, represadas pela barragem Capivara desde o final dos anos 1970, ultrapassaria os limites dessa convivência edulcorada com a natureza, similar aos apelos pelo esverdeamento dos empreendimentos imobiliários dos grandes centros urbanos, como mencionado anteriormente. Além disso, deve-se argumentar que esse acesso se dá por meio de aparatos tecnológicos, como lanchas, jet-skis, etc., ou, ironicamente, por meio de imagens digitalizadas, tomadas em câmaras fotográficas ou aparelhos telefônicos de última geração. Trata-se, portanto, como no folheto, da realização não de um sonho, mas do contato com uma natureza sonhada, intermediada por uma série de filtros culturais, como as peças publicitárias ou os mecanismos tecnológicos.

Existem, nas margens da represa de Capivara, diversos tipos de loteamentos de chácaras. Os mais antigos começaram a ser implementados no início dos anos 1980, 
mas a maior parte é do final dos anos 1990 e início dos anos 2000. Estima-se, segundo informações do setor de cadastro imobiliário da prefeitura de Alvorada do Sul, que a quantidade dessas chácaras aproxima-se de 2 mil unidades. ${ }^{6}$

Observa-se, recentemente, o deslocamento e a transformação da organização dos espaços dessas chácaras. Nos loteamentos mais antigos, datados dos anos 1980 e 1990, portanto, dos primeiros proprietários, nota-se algumas características que são muito distintas das que caracterizam as chácaras do Porto das Águas e também de recentes transformações nas antigas propriedades.

As chácaras nas margens da represa sempre tiveram um apelo quanto ao acesso às águas, indicando a possibilidade e o desejo da pesca como motivação principal para a aquisição desses terrenos. Nota-se, em muitas dessas chácaras mais antigas, a existência de trapiches sobre a represa, barcos de pesca, etc. Como acontece ao longo dos rios, como o Paraná, seriam esses os ranchos de pesca.

Mas, além dessa primeira imagem de que se trata de um local para pesca, a cobertura vegetal, isto é, o que foi plantado, revela outros aspectos. Como foi mencionado, as áreas que foram parceladas eram sítios, principalmente ocupados pela cafeicultura, ou já no processo de introdução da soja, quando da construção da represa Capivara e, portanto, do alagamento de diversas partes do seu território. $\mathrm{O}$ alagamento originou, ironicamente, uma nova possibilidade de transformação da natureza em mercadoria, agora não mais por meio da agricultura, mas, sim, atendendo ao desejo de acesso à represa.

O imaginário desse desejo é diverso, vai desde a tradicional atividade de pesca até a moderna vilegiatura. $\mathrm{Na}$ maior parte das chácaras, oriundas dos parcelamentos da década de 1990, a organização do espaço representa uma espécie de recomposição, ou recriação, de uma pequena propriedade rural, um sítio em miniatura. Existem pomares, com diversos tipos de fruta, notadamente os cítricos. E é muito comum a existência da plantação de pés de café, mandioca, cana-de-açúcar, verduras, etc. Nos casos em que os proprietários são aposentados que se tornaram residentes, existe a criação de animais domésticos, como galinhas.

Mais recentemente, no início do presente século, várias propriedades foram adquiridas e sofreram reformas, com a inclusão de piscinas, ajardinamentos, confortos domésticos, como ares-condicionados, etc. E muitas das antigas chácaras para pescaria estão se transformando em chácaras de lazer ou casas secundárias. Ou seja, as motivações para o acesso a esse tipo de chácara estão mudando rapidamente.

Mesmo assim, pode-se afirmar, com certeza, que as razões mais antigas representam o desejo de retorno ao rural. Esse desejo encontra evidências na idade e origem dos proprietários, pessoas que viveram na estrutura socioagrária da agricultura familiar da cafeicultura, hegemônica até os anos 1970, e tiveram de migrar para o mundo urbano com a modernização conservadora da agricultura imposta pelo regime militar. Nesse sentido, as chácaras seriam uma espécie de relíquia construída para atender ao desejo 
de manutenção da memória coletiva. Esse desejo de manutenção da memória não se refere apenas à saudade do rural concretamente vivido, mas, também, a uma percepção de relação com o mundo natural quebrada com a migração para o mundo urbano. Um vizinho, filho de agricultores da região, que migrou para a cidade no início dos anos 1970, tornou-se decasségui no Japão, onde permaneceu por 18 anos. Após o seu retorno, adquiriu uma chácara. Conversando sobre o porquê de ter adquirido a propriedade, ele respondeu: "Aqui eu posso ouvir o vento".

Eu sou filho de cafeicultores. Vi e vivi a transformação do mundo das pequenas propriedades e cidades em uma paisagem do agronegócio. A minha chácara tem pomares, trapiches, hortas, forno e fogão a lenha, como recriação de um mundo perdido, existem jardins com roseiras, buganvílias, grama esmeralda, mas também piscina, churrasqueira, internet, televisão por satélite. Ela está na fronteira entre os desejos da relíquia, originada da saudade do rural, e as demandas da vilegiatura contemporânea.

\section{Resumen}

En el final del siglo XX, en el dique Capivara, río Paranapanema, frontera entre los Estados de São Paulo y Paraná, surgió un nuevo proceso de incorporación de las orillas del lago a través de 'granjas' como casas secundarias. Algunos de estos emprendimientos utilizaron diversas estrategias de publicidad, como la impresión de carteles de muchos colores para la divulgación. Utilizaremos un cartel de un condominio lanzado en el inicio de los años 2000. El objetivo es hacer un análisis siguiendo dos perspectivas principales: la primera, considera las relaciones entre la sociedad de consumo, el llamado 'marketing verde' y la era de la ecología; la segunda, investiga cuales significados de naturaleza están representados en los carteles. Como hipótesis, se quiere verificar si la idea de naturaleza se habría convertido en un gran centro comercial donde se vende todos los tipos de productos $\mathrm{y}$, aun, a cuales demandas respondería la emergencia del fenómeno de las granjas en las orillas del lago de Capivara.

Palabras clave: Historia ambiental. Marketing verde. Condominios.

\section{Abstract}

By the end of the 20th century, at the Capivara dam by the Paranapanema River, on the border of the states of São Paulo and Paraná, there was a new process of real estate development on lake banks through the building of 'country houses' as second homes. Some of those real estate ventures used several advertising strategies, such as printing colourful folders for propaganda. The folder of a condominium launched in the early 2000s shall be used for analysis. That source will be analysed following two main perspectives: the first considers the relations between the consumer society, the socalled 'green marketing' and the eco-era; the second investigates which meanings of nature are represented in those folders. Considerations are made to assess if the idea of nature had been made into a big shopping centre, where all kinds of products are sold and, also, to which demands the emergence of the phenomenon of 
country houses on the banks of the Capivara Lake would respond.

Keywords: Environmental history. Green marketing. Condominiums.

\section{Notas}

1 Venda do condomínio fechado de chácaras Porto das Águas, às margens do Rio Vermelho, municípios de Porecatu/Alvorada do Sul, Paraná. Empreendimento da Vectra Construção, de Londrina. Loteamento entregue em 2003. Coleção do autor. Mais detalhes sobre o empreendimento, e sua atual configuração, podem ser encontrados em: < http://www.portodasaguas.com.br/>.

2 Turismo residencial é, segundo Hiernaux-Nicolás, "[...] aquele segmento do turismo pelo qual uma pessoa ou um grupo se desloca temporalmente até uma residência individual (casa, apartamento, motorhome, etc.) de sua propriedade, emprestada ou alugada, permanecendo por mais de 24 horas, com a finalidade de ócio" (2009, p. 110).

3 A noção de publicidade expressa por Junqueira, especialmente a proposição quanto aos significados da publicidade no mundo contemporâneo, foi, originalmente, postulada por Raymond Williams. Williams, no final dos anos 1950, escreveu o ensaio que estabelece a ideia de que a publicidade é um sistema mágico, que não vende produtos, mas que fornece distinções sociais aos compradores. Inicialmente, o ensaio fora escrito como um capítulo de $A$ longa revolução. Aparentemente, ele foi retirado desse projeto para compor uma obra coletiva sobre a publicidade, que nunca foi publicada. Apareceu, então, pela primeira vez, no volume 4 de New Left Review, em julho/ agosto de 1960, e apareceu em partes, depois, em outras publicações. Finalmente, foi traduzido e publicado no Brasil em 2011.

4 O desastre socioambiental foi um grande incêndio que atingiu mais de um milhão de hectares no estado do Paraná, em setembro de 1963. Após um longo período de seca no primeiro semestre daquele ano, ocorreram in- tensas geadas na segunda quinzena de agosto, criando as condições ideais para esse desastre socioambiental (PAIXÃO, 2015).

5 Sobre esse processo, ver: MELLO, João Cardoso de; NOVAIS, Fernando. Capitalismo tardio e sociabilidade moderna. In: SCWARCZ, Lilia Moritz (Org.). História da vida privada. São Paulo: Cia das Letras, 1998. v. 4. p. 559-659.

6 Várias informações, inseridas na sequência, foram obtidas diretamente em conversas com funcionários, comerciantes e moradores dessa cidade ou por meio de observação direta. Nesse sentido, é necessário esclarecer que o autor é proprietário, desde 2007, de uma dessas chácaras, na cidade de Alvorada do Sul, localizada em um parcelamento realizado na segunda metade dos anos 1980 .

\section{Referências}

ANGER, Débora Barbosa Corrêa. A banalização do meio ambiente: o uso mercadológico da natureza em publicidade. In: ENCONTRO DA ASSOCIAÇÃO NACIONAL DE PESQUISA E PÓS-GRADUAÇÃO EM AMBIENTE E SOCIEDADE, 3, 2006, Brasília. Anais... Brasília: Anppas, 2006. Disponível em: <http://www. anppas.org.br/encontro_anual/encontro3/arquivos/TA16-06042006-163003.DOC>. Acesso em: 30 nov. 2011.

ARRUDA, Gilmar. Turismo, natureza e história ambiental: chácaras de lazer na represa de Capivara-PR. Antíteses, Londrina, v. 6, n. 12, p. 293-317, jun./dez. 2013.

BARBOSA, Lívia. Garimpo e meio ambiente: águas sagradas e águas profanas. Estudos Históricos, Rio de Janeiro, v. 4, n. 8, p. 229-243, 1991.

GAMA, Antonio. Notas para uma geografia do tempo livre. In: SANTOS, Norberto Pinto; GAMA, Antonio (Coord.). Lazer: da libertação do tempo à conquista das práticas. Coimbra: Imprensa da Universidade de Coimbra, 2008. p. 17-28. 
HENRIQUE, Wendel. A cidade e a natureza: a apropriação, a valorização e a sofisticação da natureza nos empreendimentos imobiliários de alto padrão em São Paulo. GEOUSP Espaço e Tempo, São Paulo, n. 20, p. 65-77, 2006.

HENRIQUE, Wendel. A felicidade não tem preço, tem endereço: condomínios, loteamentos e a apropriação da natureza. Scripta Nova: Revista Electrónica de Geografía y Ciências Sociales, Barcelona, v. IX, n. 194 (14), agosto 2005. Disponível em: <http://www.ub.edu/ geocrit/sn/sn-194-14.htm>. Acesso em: 15 ago. 2013.

HENRIQUE, Wendel. O direito à natureza na cidade. Ideologias e práticas na História. 215 f. Tese (Doutorado em Geografia) - Universidade Estadual Paulista, Instituto de Geociências e Ciências, Rio Claro, 2004.

HIERNAUX-NICOLÁS, Daniel. Los imaginários del turismo residencial: experiências mexicanas. In: MAZÓN, T.; HUETE, R.; MANTECÓN, A. (Org.). Turismo, urbanización y estilos de vida. Barcelona: Icaria, 2009. p. 109-125.

HOBSBAWM, Eric J. A era dos Impérios. Rio de Janeiro, Paz e Terra, 1988.

HOWLETT, Michael; RAGLON, Rebecca. Constructing the environmental spectacle: green advertisements and the grenning corporate image, 1910-1990. Environmental History Review, v. 16, n. 4, p. 53-69, Winter 1992.

JUNQUEIRA, Antonio Helio. Construções retóricas na publicidade imobiliária brasileira contemporânea: encantamento e cinismo frente às aspirações do morar bem. In: ENCONTRO NACIONAL DE ESTUDOS DO CONSUMO, 5; ENCONTRO LUSO BRASILEIRO DE ESTUDOS DO CONSUMO, 1, 2010, Rio de Janeiro. Anais... Rio de Janeiro: 2010. Disponível em: <http://estudosdoconsumo.com.br/wp-content/uploads/2010/09/1.5-_Helio_Junqueira.pdf>. Acesso em: 25 jul. 2013.

PAIXÃO, Leticia. Seca, geada e fogo: considerações sobre um desastre ambiental (Paraná,
1963). 2015. 187 f. Dissertação (Mestrado em História) - Programa de Pós-Graduação em História, Universidade Estadual de Maringá, Maringá, 2015.

POLANYI, Karl. A grande transformação: as origens de nossa época. 2. ed. Rio de Janeiro: Campus, 2000.

SERRANO, Célia Maria de Toledo. Uma introdução à discussão sobre turismo, cultura e ambiente. In: SERRANO, Célia M. Toledo; BRUHNS, Heloisa T. (Org.). Viagens à natureza: turismo, cultura e ambiente. São Paulo: Papirus, 1997.

SILVA, Telma Domingues da. O ambiente e o turista: uma abordagem discursiva. In: SERRANO, Célia M. Toledo; BRUHNS, Heloisa T. (Org.). Viagens à natureza: turismo, cultura e ambiente. São Paulo: Papirus, 1997.

SEVCENKO, Nicolau. Introdução. O prelúdio republicano, astúcias da ordem e ilusões do progresso. In: NOVAIS, Fernando (Coord.). História da vida privada no Brasil. República: da Belle Époque à Era do Rádio. São Paulo: Cia. das Letras, 1998. p. 7-48.

WILLIAMS, Raymond. Cultura e materialismo. São Paulo: Unesp, 2011.

WORSTER, Donald. Transformações da terra: para uma perspectiva agroecológica na história. Ambiente $\mathcal{E}$ sociedade, Campinas, v. 6, n. 1, p. 23-44, jan./jul. 2003. 